\title{
Correspondence
}

\section{Treatment of the mentally ill on Leros and in Macao}

\section{DEAR SIRS}

The College has in recent years made great endeavours to highlight the plight of those subject to political abuses (Reddaway, 1989; Finlayson, 1987). I surely cannot have been the only one to have found it ironic that the Soviet Union was readmitted to the World Psychiatric Association at its recent meeting in Athens (Smith, J., 1989), against the background of much media attention to the deprivation and degradation of the inmates of the Greek Island of Leros (Merrit, 1989).

Sadly it has been left to the media to highlight the deplorable and inhumane conditions of mentally ill and mentally handicapped people such as those on Leros (Merrit, 1989) and also in Macao (Smith, C., 1989) while the college has remained strangely silent.

Surely a body as world renowned and respected as the Royal College of Psychiatrists should be doing more to address the issues raised?

C. M. TYRIE

\section{Mental Handicap Services Unit \\ Calmore, Southampton SO4 2RZ}

\section{References}

Finlayson, J. (1987) Political abuse of psychiatry with a special focus on the USSR. Bulletin of the Royal College of Psychiatrists, 11, 144-145.

MERRIT, J. (1989) The naked and the damned. The Observer, 10 September 1989.

Reddaway, P. (1989) The current situation in Soviet psychiatry regarding political abuses. Psychiatric Bulletin, 13, 529-532.

SMITH, C. (1989) Innocents behind bars. Observer Magazine, 17 September 1989.

SMITH, J. (1989) World psychiatrists readmit Soviet Union. British Medical Journal, 299, 1065.

\section{DeAR Sirs}

Dr Tyrie's point is well taken but there is a difference between the situation at Leros and that in the USSR. The College has been aware of the problems at Leros for some time but was also aware that a number of organisations have been taking active steps to do something about it. In particular, an EEC group, led by Professor Ivor Browne in Dublin, had visited Leros and made a number of recommendations. We had also received reports from various visitors subsequently. When the present situation was published I wrote in vigorous terms to the Minister of Health in
Athens, the Greek Ambassador in England and the President of the Hellenic Psychiatric Association as well as to Professor Stevanis, the President of the World Psychiatric Association. The matter was of course extensively discussed at the WPA meeting itself. International pressure and particularly pressure from the EEC is still being exerted to improve the situation there.

Another difference, which has often been discussed, is that between the politics of neglect, whereby mentally ill or handicapped people are provided with poor or no treatment, and political abuse, whereby healthy people, who are seen as deviant are sent to psychiatric hospitals and even given 'treatment' against their will. The College should be alert to both, while recognising that they are different, and have different origins.

DR J. L. T. BIRLEY President

\section{Psychotherapy within general psychiatry}

DeAR SIRS

I read with great interest Dr Thomas Freeman's paper (Psychiatric Bulletin, November 1989, 13, 593-596) which so clearly outlined the changes of the last few decades that have led to analytically trained psychiatrists no longer being hospital based with involvement in the care of all kinds of in-patients, including organic and long-stay. I entirely agree that direct clinical contact and responsibility is essential to share fully common experiences with other general psychiatrists, and in helping trainees meaningfully to integrate psychoanalytic concepts into their everyday understanding and approach to psychotic patients.

The sad fact is that while British analysts continue to make seminal contributions to our understanding of different aspects of psychotic processes, there has been a relative failure to integrate them into general psychiatry at a clinical level.

I do not see an easy way to rectify this problem. It can come only from an encouragement of interested psychiatrists to undergo analytic training, with a view to applying this knowledge in a general psychiatric setting. Also there is a need to recreate suitable posts for this in the NHS. The only two in-patient specialist analytic posts in London at Shenley and the Maudsley Hospitals have now gone. The British Psychoanalytical Society has been concerned over the trend of the falling ratio of medics compared to 